\title{
OPERATIONAL NEAR REAL TIME RICE AREA MAPPING USING MULTI-TEMPORAL SENTINEL-1 SAR OBSERVATIONS
}

\author{
J.D.Mohite ${ }^{1 *}$ S.A.Sawant ${ }^{1}$, A. Kumar ${ }^{2}$, M. Prajapati ${ }^{2}$, S. V. Pusapati ${ }^{1}$, D. $\operatorname{Singh}^{1}$, S. Pappula ${ }^{1}$ \\ ${ }^{1}$ TCS Research and Innovation, Tata Consultancy Services, India - (jayant.mohite, suryakant.sawant, subhadravarma.pusapati, \\ dineshkumar.singh, srinivasu.p)@tcs.com \\ ${ }^{2}$ College of Agricultural Information Technology, Anand, India
}

Commission IV, WG IV/6

KEY WORDS: Rice area mapping, Sentinel 1, Random Forest, Classification, Google Earth Engine

\begin{abstract}
:
Spatio-temporal crop phenological information helps in understanding trends in food supply, planning of seed/fertilizer inputs, etc. in a region. Rice is one of the major food sources for many regions of the world especially in monsoon Asia and accounts for more than $11 \%$ of the global cropland. Accurate, on-time and early information on spatial distribution of rice would be useful for stakeholders (cultivators, fertilizer/pesticide manufacturers and agriculture extension agencies) to effectively plan supply of inputs, market activities. Also, government agencies can plan and formulate policies regarding food security. Conventional methods involves manual surveying for developing spatio-temporal crop datasets while remote sensing satellite observations provide cost effective alternatives with better spatial extent and temporal frequency. Remote sensing is one of the effective technologies to map the areal extent of the crops using optical as well as microwave/Synthetic Aperture RADAR (SAR) sensors. Cloud cover is the major problem faced in using the optical datasets during monsoon (June to Sept. locally called Kharif season). Hence, Sentinel-1 C-band (center frequency: 5.405 GHz) RADAR sensor launched by European Space Agency (ESA) which has an Interferometric Wide-swath mode (IW) with dual polarization (VV and $\mathrm{VH}$ ) has been used for rice area mapping. Limited studies have attempted to establish operational early season rice area mapping to facilitate local governance, agri-input management and crop growers. The key contribution of this work is towards operational near real time and early season rice area mapping using multi-temporal SAR data on GEE platform. The study has been carried out in four districts viz., Guntur, Krishna, East Godavari and West Godavari from Andhra Pradesh (AP), India during the period of Kharif 2017. The study region is also called as coastal AP where rice transplanting during the Kharif season is carried out during mid Jun. till Aug. and harvesting during Oct. to mid Dec. months. The training data for various classes viz, Rice, NonRice-Agriculture, Waterbodies, Settlements, Forest and Aquaculture have been obtained from GEE, Global Land Cover (GLC) layers developed by ESA and field observations. We have evaluated the performance of Random Forest (RF) classifier by varying the number of trees and incrementally adding the SAR images for model training. Initially the model has been trained considering two images available from mid June 2017. Further, various models have been trained by adding one consecutive image till end of August 2017 and classification performance has been evaluated on validation dataset. The classified output has been further masked with agriculture non-agriculture layer derived from global land-cover layer obtained from ESA. Analysis shows that incremental addition of temporal observations improves the performance of the classifier. The overall classification accuracy ranges between 78.11 to $87.00 \%$. We have found that RF classifier with 30 trees trained on six images available from mid June till end August performed better with classification accuracy of $87.00 \%$. However, accuracy assessment performed using independent stratified random sampling approach showed the classification accuracy of $84.45 \%$. An attempt is being made to follow the proposed approach for current (i.e. 2018) season and provide incremental rice area estimates in near real-time.
\end{abstract}

\section{INTRODUCTION}

Rice is the staple food for half of the world's population especially in monsoon Asia and accounts for more than $11 \%$ of the global cropland (FAO, 2009). The spatio-temporal distribution and dynamics of rice cultivation in a region helps to understand growing food demand, water scarcity, etc. Accurate and on-time information on spatial distribution of rice would be useful for stakeholders (cultivators, fertilizer/pesticide manufacturers and agriculture extension agencies) to effectively plan supply of inputs, market activities. Also, government agencies can plan and formulate policies regarding food security. In addition, the data on rice area would be useful as an input to estimate crop health, water demand, crop yield at field/regional level. From crop insurance standpoint near-real time crop area maps are useful for

\footnotetext{
*Corresponding author
}

identifying the areal extent of prevented/delayed sowing to facilitate the timely settlement of insurance cover.

Traditional approach of manually visiting the farms for surveys and crop cutting experiments is very costly and time consuming as compared to the information generated through remote sensing. Remote sensing is one of the effective technology to map the areal extent of the crops. Rice area mapping at field, regional and national scale has been carried out in the past using various approaches which involves use of single date or time series optical as well as microwave/Synthetic Aperture RADAR (SAR) data (Qin et al., 2015, Nguyen et al., 2015, Neetu et al., 2014). Karydas et al., (Karydas et al., 2015) designed an algorithm for rice mapping using time series of Landsat- 8 observations. Time series images of Landsat-8, MODIS and PALSAR images were used by (Wang et al., 2015) to map paddy rice planting areas. Pixel and phenology based algorithms have been implemented by (Qin et 
al., 2015) on time series datasets of MODIS, Landsat 7 and 8 to map the rice areas. However, the use of optical remote sensing data is limited during Kharif season (starts in mid Jun. and ends in Nov.) due to cloud cover and weather dependency. The SAR has capabilities to penetrate through the clouds, captures the data day-night and are weather independent which makes them attractive for rice area mapping during Kharif season. Numerous attempts have been taken in the past to map the rice areas using multi-temporal SAR data based on the temporal variations in the SAR backscatter (dB) signal (Kurosu et al., 1995, Nguyen et al., 2015, Choudhury and Chakraborty, 2006). Spatio-temporal mapping of growing pattern of rice and other crops have been carried out using multi-date RISAT-1 MRS data in Barddhaman district of West Bengal (Neetu et al., 2014). Wu et al., (Wu et al., 2011) reported that the $\mathrm{HH} / \mathrm{VV}$ ratio was best for discriminating rice from bananas, forest, and water. Literature review suggests that most of the studies have been limited to map paddy rice from Cband SAR data either by using single polarization $(\mathrm{HH})$ or a combination of different polarizations ( $\mathrm{HH} / \mathrm{VV}, \mathrm{HH} / \mathrm{HV}$ or $\mathrm{VV} / \mathrm{VH})$. However, only a few of them have investigated early season VV and $\mathrm{VH}$ backscatter time series for operational near-real time rice area mapping. Furthermore, to our knowledge, no work using near real time Sentinel-1 data for rice mapping in the coastal AP has been published yet. Also, most of the studies have attempted individual machine learning/rule based algorithms along with full season time series to estimate the rice area. We have attempted to use early season time series to provide early information about estimated acreage of rice in a study region, to the planners and decision makers. The key objective of this study is development of operational near-real time and early season rice area mapping framework using multi-temporal Sentinel-1 SAR data on GEE platform. Sentinel-1A and $1 \mathrm{~B}$ are the next generation of C-band (center frequency: $5.405 \mathrm{GHz}$ ) radar sensors with a 12-day revisit time. The standard L1 product of Sentinel-1A has an Interferometric Wide-swath mode (IW) with dual polarization (VV/VH), and a spatial resolution of $5 \mathrm{~m}$ and $20 \mathrm{~m}$ in the range and azimuth directions, respectively. This open access relatively high spatiotemporal resolution provides an outstanding data source for rice mapping. Information on study area, datasets used, and overall framework of rice area mapping has been described in Section 2. Details about the data analysis approach, results and classification performance using various multi-date images are presented in Section 3. Finally, summary, conclusions and future prospects of the study are described in Section 4.

\section{OPERATIONAL RICE AREA MAPPING FRAMEWORK}

\subsection{Study Area}

The study on rice area mapping has been carried out in the four districts from coastal AP namely Guntur, Krishna, West and East Godavari. Study region has rich agricultural land, owing to the delta of the Godavari and Krishna rivers (Figure 1). The prosperity of the region can be attributed to its rich agricultural land and abundant water supply from these two rivers. Rice is the predominant crop cultivated in the region. The crop is cultivated mainly during two seasons namely Kharif which starts from mid Jun. till Nov. and Rabi which starts from mid Dec. and ends in May. Other crops cultivated in the region are Sugarcane, Cotton, Chilli, Pulses, Coconut, etc.

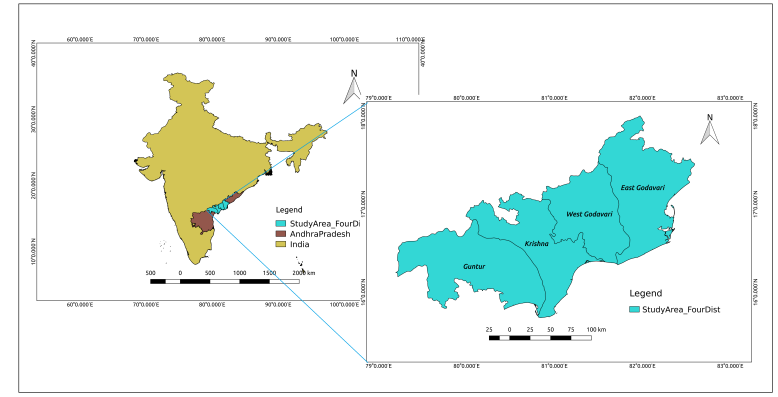

Figure 1. Study Area

\subsection{Datasets Used}

In this study we have used Sentinel-1A and 1B satellite imagery, GLC dataset (ESA, 2017a) developed by ESA, ground truth data collected from the field visits and mKRISHI $₫$ and crop acreage statistics from department of agriculture, Andhra Pradesh.

2.2.1 Sentinel-1 Data and Preprocessing: Sentinel-1 satellite was launched by the ESA. The Sentinel-1 mission comprises a constellation of two polar-orbiting satellites (Sentinel 1A and 1B), operating day and night performing C-band synthetic aperture radar imaging, enabling them to acquire imagery regardless of the weather. The Sentinel-1A SAR instrument operates at $5.405 \mathrm{GHz}$ (C-band corresponding to a radar wavelength of about $5.6 \mathrm{~cm}$ ), containing $\mathrm{VH}$ and $\mathrm{VV}$ polarizations with the revisit cycle of 12 days and a spatial resolution of $5 \mathrm{~m}$ by $20 \mathrm{~m}$ in the range and azimuth directions, respectively (ESA, 2017b). It has an equivalent number of looks of five, and an image resolution of $10 \mathrm{~m}$ (Cazals et al., 2016). We have accessed the Sentinel$1 \mathrm{~A}$ and 1B backscatter images from GEE platform (Gorelick et al., 2017). The GEE collection includes the S1 Ground Range Detected (GRD) scenes, processed using the Sentinel-1 Toolbox to generate a calibrated, ortho-corrected product. Each scene is pre-processed with Sentinel-1 toolbox using the thermal noise removal, radiometric calibration and terrain correction. The final terrain corrected values are transformed to decibels $(\mathrm{dB})$ via $\log$ scaling and quantized to 16 bits. In this study we have used both $\mathrm{VV}$ and VH polarization. The S-1A and S-1B images available from 22 June 2017 till 2 Sept. 2017 were accessed from GEE datasets and used for analysis.

2.2.2 Global Land Cover Dataset: ESA under their Climate Change Initiatives (CCI) has developed 300m annual GLC maps for 24 years spanning from 1992-2015 (ESA, 2017a). The CCI dataset consist of 22 classes. We have derived Agriculture (class values $10,20,30,40$ ) vs Non-Agriculture mask (other remaining class values) using this dataset. The CCI data was available at $300 \mathrm{~m}$ spatial resolution which has been resampled to $10 \mathrm{~m}$ spatial resolution to match with Sentinel resolution. This agriculture non-agriculture mask at $10 \mathrm{~m}$ is used to reduce misclassification and get more fine-tuned output classified maps.

2.2.3 Digital Elevation Model: The Advanced Space-borne Thermal Emission and Reflection Radiometer (ASTER) Global Digital Elevation Model (GDEM) was developed jointly by the U.S. National Aeronautics and Space Administration (NASA) and Ministry of Economy, Trade, and Industry (METI) Japan. ASTER DEM covering the study area was accessed from GEE collection (Gorelick et al., 2017). ASTER DEM is having a spatial resolution of $30 \mathrm{~m}$ which was resampled to $10 \mathrm{~m}$ to match it 
Sentinel-1 resolution. Further, DEM tiles were mosaicked and slope in percent was estimated and used as one of the features in the classification.

2.2.4 Ground Truth data from Field Visits: Rural Participatory Sensing based android mobile application (Mohite et al., 2015) was used for ground truth data collection from the fields. The plot and crop information has been collected using the mobile application. The plot registration includes capturing the GPS co-ordinates of the plot and crop cultivation details from the registered plot such as crop name, variety, sowing/transplanting date, etc. The ground truth data on locations and sowing information of rice and other crops was also taken from mKRISHIR(Pande et al., 2009) database. Further, we have used GEE interface with Google Maps overlay as a reference for generating training boundaries of settlements, forest and waterbodies. The data obtained from these sources have been used for model development and validation. In addition to this, statistics on rice acreage for Kharif 2017 season was obtained from the Department of Agriculture web portal, Andhra Pradesh and used for cross-validation of our proposed approach.

\subsection{Overall Approach}

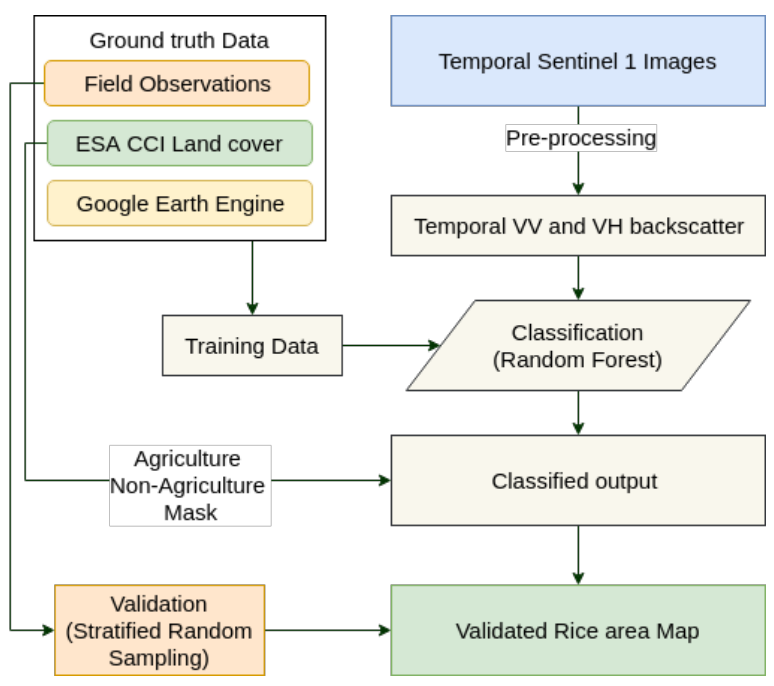

Figure 2. Rice Area Mapping Framework

In the study area, rice is cultivated during two main seasons namely Kharif and Rabi. The Kharif season starts with the onset of monsoon that is during mid. June and ends in Nov. Whereas, Rabi season starts in Dec. and ends in May. Figure 2 shows the overall rice area mapping framework. In the study area rice is transplanted during July and August. The Rice transplanting is followed by 10-15 days ponding of water in the fields. The ponding in open field followed by rice transplanting and growth in crop canopy is well captured using SAR observations. To capture this cultivation practice we have considered Sentinel-1A and 1B images available from end of June till start of Sept. 2017. Data available in IW with dual polarization (VV and VH) have been used for rice area mapping. We have evaluated the performance of RF classifier by varying the number of trees and incrementally adding the Sentinel-1A and $1 \mathrm{~B}$ images for the training. Initially the classifier has been trained considering two images available from mid June 2017. Further, classifier has been trained by adding one consecutive image till end of the August and classification performance has been evaluated on validation dataset. Finally, GLC agriculture non-agriculture mask at $10 \mathrm{~m}$ resolution has been applied on classified output to reduce misclassification (ESA, 2017a). The classification accuracy has been also estimated using stratified random sampling method proposed by (Olofsson et al., 2014).

\section{RESULTS AND DISCUSSIONS}

The Land Use/Land Cover (LU/LC) class separability was performed for rice, non-rice agriculture, forest, settlement and water. Fig 3 and 4 shows the box plots for LU/LC classes in VH and VV polarization respectively. It is observed that during the Kharif season transplanting window (i.e. July and August months) average backscatter for rice is lower as compared to other months and this is because of the ponding of water in the fields. Also there is a clear separation of rice from water-bodies, settlements and forest in both VH and VV polarizations. For July scenes rice is mixing with non-rice agriculture whereas separation is for other months of Kharif season.

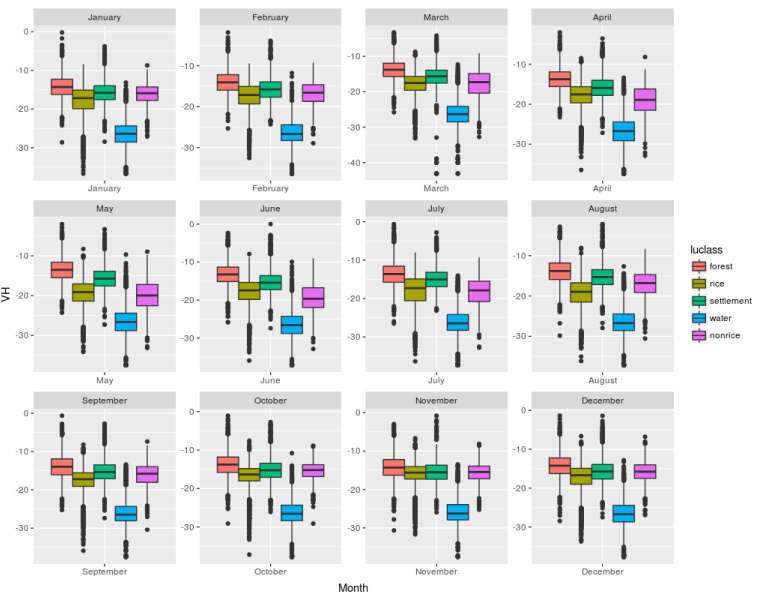

Figure 3. Box Plot for LU/LC Classes in VH Polarization

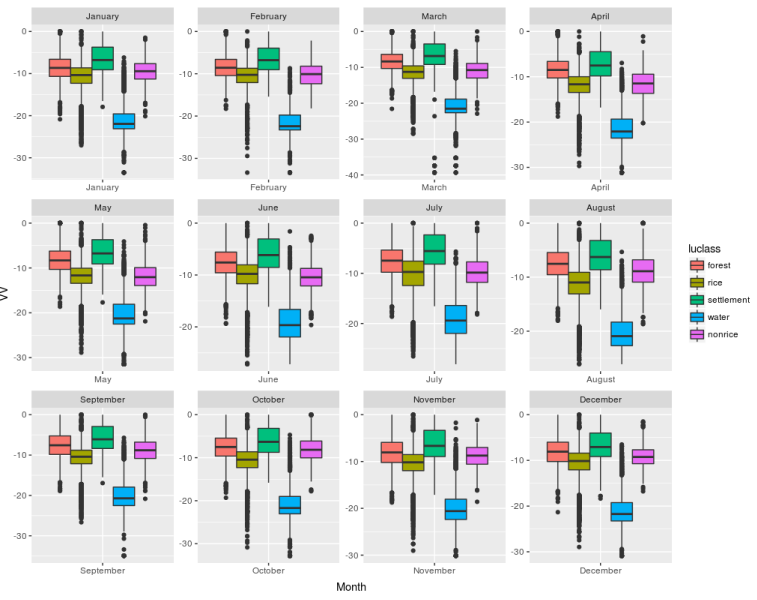

Figure 4. Box Plot for LU/LC Classes in VV Polarization

The random forest classifier has been trained considering two satellite passes available from mid June to generate classification map for 5 July, 2017 (total five features were used for the analysis i.e. two VV and VH bands for each date and slope in percent). Total size of the training data for all classes was 18454 pixels and it was divided into $70 \%$ of the data for model training whereas remaining $30 \%$ data for model validation. To assess 
the classification accuracy the classifier was trained for number of trees from 5 to 45 with a interval of five trees. Five classifier iterations were performed for each combination of training data and number of trees to average out the classification accuracy. Further, each available image (VV and VH bands) was added as the features and classifier was re-trained. In total we have trained the classifier by considering 2 to 7 dates (i.e. 5 to 15 features) respectively. The overall classification accuracy ranges between 78.11 to $87.00 \%$. Further, the classification accuracy assessment was also performed using stratified random sampling approach. Hundred samples from rice and all other non-rice classes were selected and accuracy was estimated by comparing them with the actual class value (collected from field observations). Table 1 shows the validation accuracy and accuracy based on stratified random samples.

\begin{tabular}{|l|l|l|l|}
\hline Date & $\begin{array}{l}\text { Features } \\
\text { Used }\end{array}$ & $\begin{array}{l}\text { Validation } \\
\text { Accuracy } \\
(\%)\end{array}$ & $\begin{array}{l}\text { Stratified } \\
\text { Random } \\
\text { Sampling } \\
\text { Accuracy } \\
(\%)\end{array}$ \\
\hline 5 July 2017 & 5 & 78.11 & - \\
\hline 18 July 2017 & 7 & 77.82 & - \\
\hline 30 July 2017 & 9 & 81.02 & - \\
\hline 12 Aug 2017 & 11 & 83.56 & - \\
\hline 24 Aug 2017 & 13 & 83.62 & - \\
\hline 2 Sept 2017 & 15 & 87.00 & 84.45 \\
\hline
\end{tabular}

Table 1. Performance of RF for Multi-Date Scenarios

Performance of the RF classifier was evaluated for varying number of trees and scenarios (Figure 5). It is observed that for most of the scenarios RF classifier with 30 number of trees was performing better and thereafter minimal improvement in the classification accuracy.

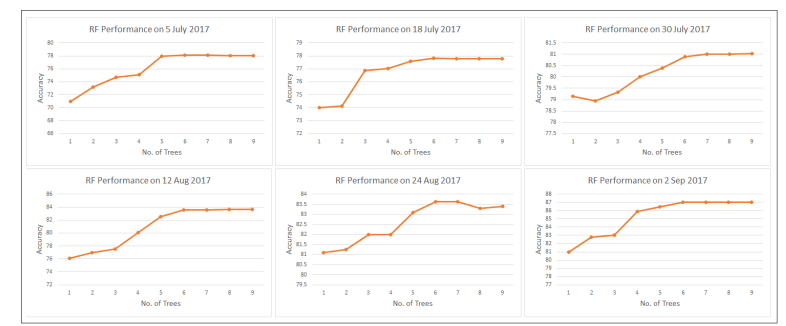

Figure 5. Average Accuracy using RF for Different Number of Trees

We have merged all non-rice classes and generated classified maps for rice vs non-rice. Figures 6 to 11 show the rice vs nonrice classified map for the season from 5 Jul. 2017 to 2 Sept. 2017. As season proceeds the late-transplanted rice area is added in the result. The sharp increase in the rice area from $18 \mathrm{Jul}$. to 12 Aug. is due to majority of the fields are transplanting during this period. In Guntur district rice transplantation starts after end of July, similar trend is observed in both classified maps and during the field visits. The rice area maps generated during the transplanting period will help to track the rice cultivation and this information could be useful to various stakeholders like government to estimate prevented sowing, agri-input companies to manage the supply of inputs like seeds, fertilizers, pesticides, etc.

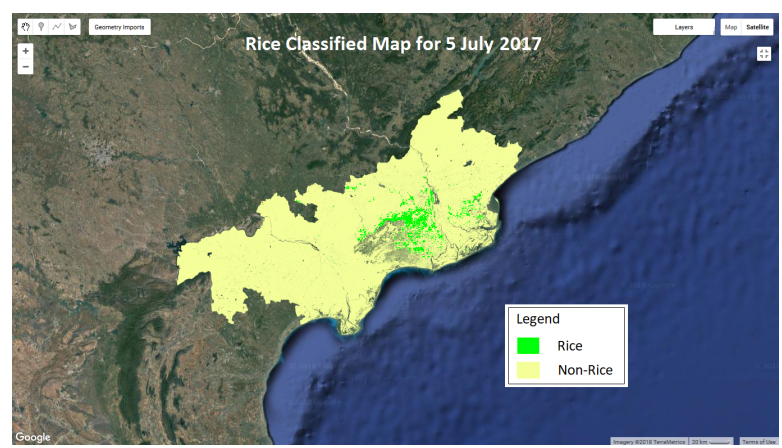

Figure 6. Rice Classified Map for 5 July 2017

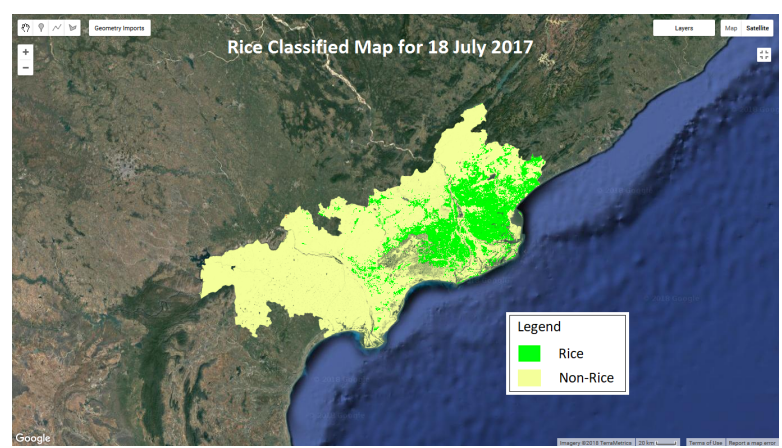

Figure 7. Rice Classified Map for 18 July 2017

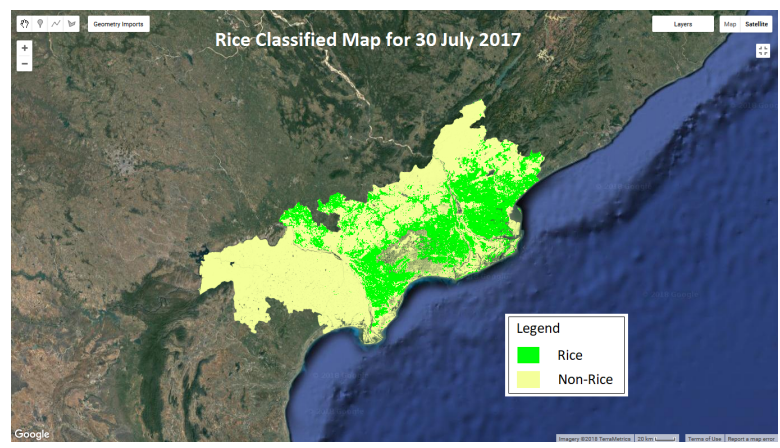

Figure 8. Rice Classified Map for 30 July 2017

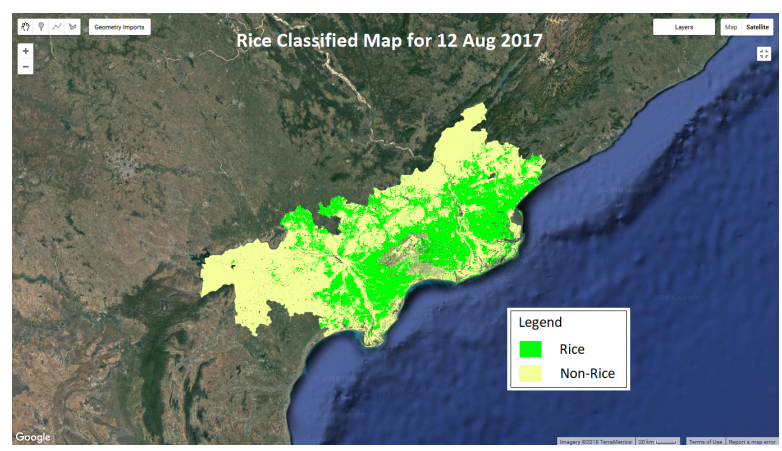

Figure 9. Rice Classified Map for 12 Aug 2017

The results were compared with the statistics available from Department of Agriculture, Government of AP. Table 2 shows the comparison between rice area obtained using proposed approach, government statistics and percent difference. The total difference 


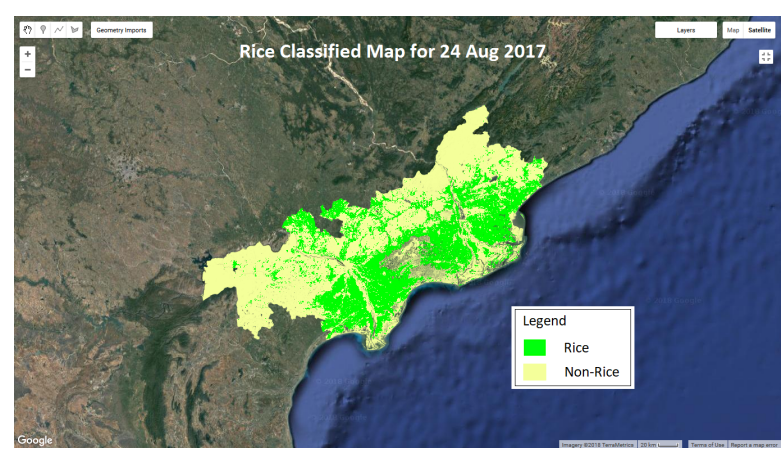

Figure 10. Rice Classified Map for 24 Aug 2017

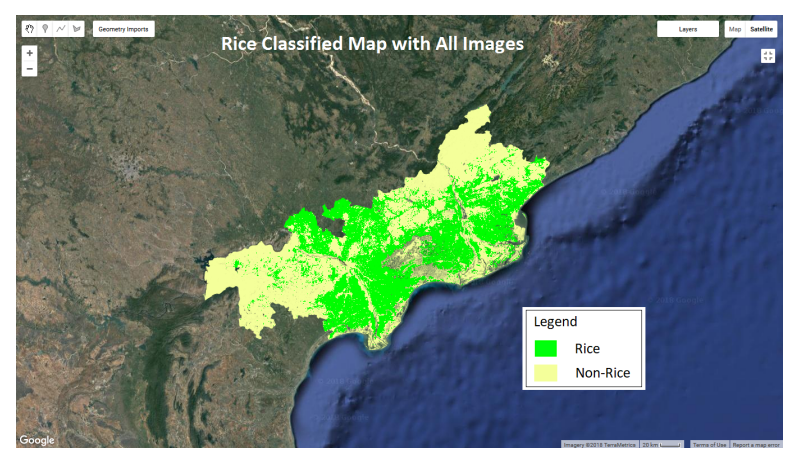

Figure 11. Rice Classified Map with All Images

is less than $10 \%$.

\begin{tabular}{|l|l|l|l|l|}
\hline $\begin{array}{l}\text { S. } \\
\text { N. }\end{array}$ & District & $\begin{array}{l}\text { Proposed } \\
\text { approach } \\
(, 000 \mathrm{Ha})\end{array}$ & $\begin{array}{l}\text { Govt. } \\
\text { Statistics } \\
(, 000 \mathrm{Ha})\end{array}$ & $\begin{array}{l}\text { Percent } \\
\text { Differ- } \\
\text { ence } \\
(\%)\end{array}$ \\
\hline 1 & Guntur & 199.421 & 208.771 & -4.48 \\
\hline 2 & Krishna & 253.556 & 232.456 & 9.08 \\
\hline 3 & East Godavari & 241.13 & 229.178 & 5.22 \\
\hline 4 & West Godavari & 249.116 & 232.323 & 7.23 \\
\hline
\end{tabular}

Table 2. Comparison of area obtained using proposed approach with government statistics

\section{SUMMARY AND CONCLUSIONS}

Early season information on the spatio-temporal dynamics of rice area is of crucial importance to the various government organizations, fertilizer companies and farmers for input planning and decision making. The SAR based sensors are one of the fast and effective ways to get accurate and early season information on rice area. In this study rice area mapping has been carried out for four districts of coastal Andhra Pradesh during Kharif 2017 season using multi-date images of Sentinel-1 (SAR sensor) with update frequency of 12 days and 10 meter spatial resolution. We have evaluated the performance of RF classifier by changing the number of trees and incrementally adding the Sentinel-1 images. The classified output has been further masked with agriculture non- agriculture layer derived from GLC layer obtained from ESA. The mixing between rice and aquaculture was removed using GLC agriculture non-agriculture mask. Classifier performance improved by incremental addition of image to training data. The overall classification accuracy ranges between 78.11 to $87.00 \%$. We have found that RF classifier with 30 trees trained on six images available from mid June till end August performed better with classification accuracy of $87.00 \%$. Further, accuracy assessment performed using independent stratified random sampling approach showed the classification accuracy of $84.45 \%$. We conclude that, early season Sentinel-1 data in both VV and VH polarization is useful for operational near real time rice area mapping. The generated rice area maps have potential to plan the agriculture input supply activities, crop insurance, etc. An attempt is being made to follow the proposed approach for current (i.e. 2018 onwards) cropping season and provide incremental rice area estimates in near-real time.

\section{REFERENCES}

Cazals, C., Rapinel, S., Frison, P.-L., Bonis, A., Mercier, G., Mallet, C., Corgne, S. and Rudant, J.-P., 2016. Mapping and characterization of hydrological dynamics in a coastal marsh using high temporal resolution sentinel-1a images. Remote Sensing 8(7), pp. 570 .

Choudhury, I. and Chakraborty, M., 2006. Sar signature investigation of rice crop using radarsat data. International Journal of Remote Sensing 27(3), pp. 519-534.

ESA, 2017a. $300 \mathrm{~m}$ annual global land cover time series from 1992 to 2015. https://www.esa-landcover-cci.org/?q=node/175.

ESA, 2017b. Sentinel-1. https://sentinel.esa.int/web/sentinel/ missions/sentinel-1.

FAO, 2009. How to feed the world in 2050. Rome, FAOSTAT.

Gorelick, N., Hancher, M., Dixon, M., Ilyushchenko, S., Thau, D. and Moore, R., 2017. Google earth engine: Planetary-scale geospatial analysis for everyone. Remote Sensing of Environment.

Karydas, C., Toukiloglou, P., Minakou, C. and Gitas, I., 2015. Development of a rule-based algorithm for rice cultivation mapping using landsat 8 time series. Third International Conference on Remote Sensing and Geoinformation of the Environment (RSCy2015), Proc. of SPIE.

Kurosu, T., Fujita, M. and Chiba, K., 1995. Monitoring of rice crop growth from space using the ers-1 c-band sar. IEEE Transactions on Geoscience and Remote Sensing 33(4), pp. 1092-1096.

Mohite, J., Karale, Y., Gupta, P., Kulkarni, S., Jagyasi, B. and Zape, A., 2015. Rups: Rural participatory sensing with rewarding mechanisms for crop monitoring. In: Pervasive Computing and Communication Workshops (PerCom Workshops), 2015 IEEE International Conference on, IEEE, pp. 378-383.

Neetu, Prashnani, M., Singh, D. K., Joshi, R. and Ray, S. S., 2014. Understanding crop growing pattern in barddhaman district of west bengal using multi-date risat $1 \mathrm{mrs}$ data. The International Archives of the Photogrammetry, Remote Sensing and Spatial Information Sciences. ISPRS Technical Commission VIII Symposium. 
Nguyen, D., Clauss, K., Cao, S., Naeimi, V., Kuenzer, C. and Wagner, W., 2015. Mapping rice seasonality in the mekong delta with multi-year envisat asar wsm data. Remote Sensing 7(12), pp. $15868-15893$.

Olofsson, P., Foody, G. M., Herold, M., Stehman, S. V., Woodcock, C. E. and Wulder, M. A., 2014. Good practices for estimating area and assessing accuracy of land change. Remote Sensing of Environment 148, pp. 42-57.

Pande, A., Jagyasi, B., Kimbahune, S., Doke, P., Mittal, A., Singh, D. and Jain, R., 2009. Mobile phone based agro-advisory system for agricultural challenges in rural india. IEEE Conference on Technology for Humanitarian Challenges.

Qin, Y., Xiao, X., Dong, J., Zhou, Y., Zhu, Z., Zhang, G., Du, G., Jin, C., Kou, W., Wang, J. and Li, X., 2015. Mapping paddy rice planting area in cold temperate climate region through analysis of time series landsat $8(\mathrm{oli})$, landsat $7(\mathrm{etm}+)$ and modis imagery. ISPRS Journal of Photogrammetry and Remote Sensing 105, pp. 220-233.

Wang, J., Xiao, X., Qin, Y., Dong, J., Zhang, G., Kou, W., Jin, C., Zhou, Y. and Zhang, Y., 2015. Mapping paddy rice planting area in wheat-rice double-cropped areas through integration of landsat-8 oli, modis, and palsar images. Nature Scientific Reports 5 .

Wu, F., Wang, C., Zhang, H., Zhang, B. and Tang, Y., 2011. Rice crop monitoring in south china with radarsat-2 quad-polarization sar data. IEEE Geosci. Remote Sensing Lett. 8, pp. 196-200. 